\title{
ANALISIS OPTIMASI SPACE DIVERSITY PADA LINK MICROWAVE MENGGUNAKAN ITU MODELS
}

\section{ANALYSIS OF SPACE DIVERSITY OPTIMIZATION ON MICROWAVE LINKS USING ITU MODELS}

\author{
Zein Hanni Pradana ${ }^{1}$,Ade Wahyudin² \\ ${ }^{1,2}$ Fakultas Teknik Telekomunikasi \& Elektro, Institut Teknologi Telkom Purwokerto \\ 12zeindana@ittelkom-pwt.ac.id,_=adewahyudin@ittelkom-pwt.ac.id
}

\begin{abstract}
Abstrak
Dalam sebuah Link Microwave, sinyal terima harus memenuhi syarat LOS (Line of Sight). LOS adalah perambatan radio gelombang mikro dari antena pengirim ke antena penerima dengan jalur transmisi bebas. Pada penerima, sinyal yang diterima tidak hanya berasal dari sinyal LOS tetapi sinyal yang dipantulkan dari permukaan bumi. Sinyal dari beberapa pantulan ini sering disebut dengan multipath. Penerimaan sinyal di penerima memang merupakan sinyal penambahan dari sinyal LOS dan juga sinyal multipath, namun sinyal-sinyal multipath ini justru akan menimbulkan interferensi yang dapat menyebabkan fading atau perubahan gelombang elektromagnetik yang diterima. Untuk menanggulangi fading ini maka diperlukan optimasi yang meningkatkan kualitas Link Microwave. Dengan menggunakan space diversity menggunakan ITU models, fading dapat berkurang dapat dilihat pada availability meningkat dari 99,96949\% menjadi $99,98767 \%$. Diversity Receive Signal tertinggi didapatkan pada 200 $\lambda$, dengan nilai Diversity Receive Signaladalah $-83,94 \mathrm{dBm}$.
\end{abstract}

\section{Katakunci:LOS, multipath, fading, availability, space diversity}

\begin{abstract}
In a Microwave Link, the receive signal must fulfill the LOS (Line of Sight) requirement. LOS is the microwave radio propagation from the tranceiver antenna to the receiver antenna with a free transmission line. At the receiver, the received signal is not only derived from the LOS signal but also the reflected signal from the earth's surface. The signals of these reflections are often called multipaths. The reception of signals in the receiver is an addition signal of the LOS signal as well as the multipath signal, but these multipath signals will actually cause interference which may cause fading or the changes of received electromagnetic waves. To overcome this fading, an optimization is important to improve the quality of Microwave Link. By using space diversity using ITU models, the availability is increased from $99.96949 \%$ to $99.98767 \%$. The highest Diversity Receive Signal is obtained at $200 \lambda$, the Diversity Receive Signal is $-83.94 \mathrm{dBm}$.
\end{abstract}

Keywords:LOS, multipath, fading, availability, space diversity

\section{PENDAHULUAN}

Telekomunikasi berperan sangat penting dalam modernisasi kehidupan manusia. Perkembangan teknologi informasi dan telekomunikasi yang sangat pesat menjadikan pekerjaan manusia menjadi lebih mudah untuk dilakukan. Teknologi selular merupakan salah satu hal terpenting sebagai sarana komunikasi untuk bertukar informasi melalui voice, data maupun keduanya. Untuk mendukung jaringan selular yang baik maka dibutuhkan perancangan backhaul menggunakan link microwave. Link microwave merupakan lintasan komunikasi tanpa kabel yang memanfaatkan udara bebas sebagai media transmisi untuk membawa sinyal informasi. 
Komunikasi radio microwave memanfaatkan udara bebas sebagai media transmisi untuk membawa sinyal informasi [2]. Komunikasi radio microwave diterapkan sebagai penghubung antar Base Station Tower (BTS) dalam pengiriman informasi dengan kapasitas yang besar.

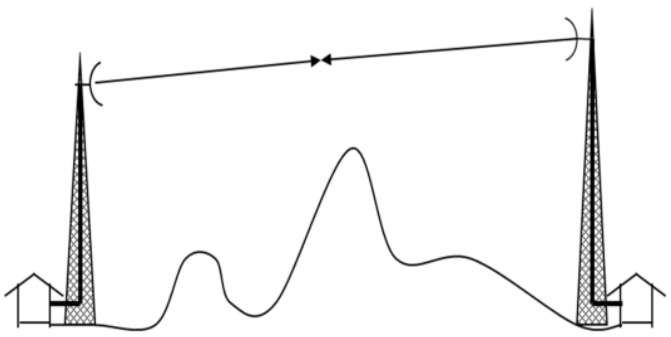

Gambar 1 Komunikasi dua BTS yang LOS[2]

Stasiun yang digunakan, baik stasiun pemancar maupun penerima ditempatkan pada lokasi yang tinggi dan pada menara antena yang tinggi pula agar transmisi dapat mencakup daerah LOS yang maksimum sehingga dapat diperoleh suatu lintasan gelombang yang bersifat langsung (direct signal path) [3]. Propagasi LOS gelombang mikro menggunakan gelombang radio atau Radio Frequency (RF), yang jugamerupakan gelombang elektromagnetik. Gelombang radio melalui berbagai lintasan dengan beberapa mekanisme perambatan dasar, yaitu Line of Sight (LOS) yang merupakan lintasan gelombang radio dan mengikuti garis pandang yang berarti bahwa antara antena pemancar dan antena penerima tidak ada penghalang (obstacle), yang menghalangi lintasan perambatan gelombang mikro.

Namun dalam sinyal yang diterima pada penerima sinyal yang diterima tidak hanya sinyal LOS [4]. Sinyal yang diterima bisa saja sinyal langsung dan juga sinyal yang terpantulkan dari batu, tumbuhan, gedung, bahkan dapat pula disebabkan oleh bentuk kurva bumi itu sendiri, atau efek yang diakibatkan dari penghalang seperti pohon dan bangunan. Sinyal yang diterima melalui gelombang yang merambat melalui jalan yang berbeda ini disebut dengan multipath.

Sinyal multipath yang berbeda fasa dengan sinyal LOS akan melemahkan bahkan bisa saling menghilangkan [4]. Pelemahan atau fluktuasi sinyal ini sering disebut dengan fading. Multipath Fading merupakan diterimanya gelombang yang merambat melalui jalan yang berbeda, sehingga terjadi saling interferensi.

Berdasarkan penelitian sebelumnya, berjudul "Diversity: A Fading Reduction Technique" oleh N. Sachdeva dan D. Sharma, menunjukan bahwa space diversity dapat menanggulangi multipath fading pada link microwave. Pada pembahasan terdapat analisis mengenai pengaruh space diversity terhadap jaringan link microwave agar memenuhi kondisi system komunikasi yang bekerja dengan optimal dalam melakukan performansi komunikasi link microwave. [5]. Pada penelitian lain, "Space Diversity for Wireless Communication-A Review" Oleh N. Desai dan G. D. Makawana, menunjukan bahwa space diversity mampu mengurangi pengaruh dari multipath fading dengan memperhatikan transmit diversity dan space time codes sehingga mampu menghasilkan efisiensi dan meningkatkan bit rate pengiriman sinyal [6]. Sedangkan penggunaan model ITU, mengacu pada penelitian "Comparison analysis of passive repeater links prediction using methods: Barnett Vigants \& ITU models" oleh A. Hikmaturokhman, A. Wahyudin, A. S. Yuchintya dan T. A. Nugraha, menyimpulkan bahwa pengunaan model ITU mampu meninggkatkan availability hingga 99,9999133\%, sehingga dapat direkomdasikan dalam penelitian ini [7].

Simulasi perancangan link microwave dapat menggunakan software Pathloss 5.0 dan space diversity dengan model antenna MIMO 2x2. Pathloss 5.0 berfungsi sebagai alat bantu untuk komunikasi radio microwave[1]. Yang harus diperhatikan dalam sebuah perancangan adalah 
kualitas dari link jaringan selular, obstacle yang ada dari daerah perencanaan sehingga didapatkan hasil link budget untuk perencanaan yang sebenarnya.

\section{DASARTEORI/MATERIALDANMETODOLOGI}

\subsection{Space Diversity}

Skema diversity yang paling umum adalah space diversity. Antena digunakan untuk mencapai salinan yang berbeda dari sinyal yang ditransmisikan. Menggunakan dua antena dengan jarak antara kedua antena dan keterlambatan fase membuat sinyal multipath tiba di antena berbeda memudar.

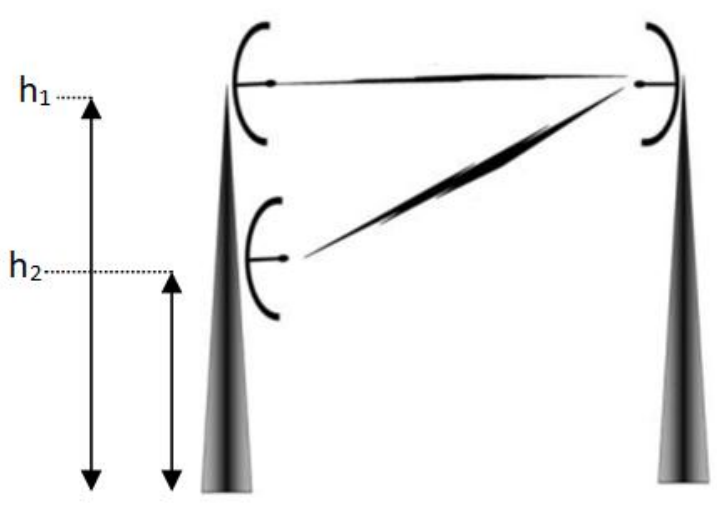

Gambar 2 Space Diversity[5]

Pada Space Diversity perlu ditentukan terlebih dahulu selisih ketinggian antena. Untuk menentukan selisih ketinggian antena digunakan persamaan dibawah ini.[2]

$$
\Delta h=h_{1}-h_{2}=p \lambda
$$

Keterangan :

$p \quad$ : merupakan rentang antara 100 sampai dengan 200

$\lambda \quad$ : merupakan panjang gelombang

$\lambda$ dapat dihitung dengan menggunakan persamaan 2.[2]

$$
\lambda=\frac{c}{f}
$$

Keterangan :

c : Kecepatan cahaya $\left(3 \times 10^{8}\right)$

$f \quad$ : Frekuensi (dalam heartz)

\subsection{Availability}

Availability merupakan kehandalan sistem. Kebalikan dari availability adalah unavailability. Unavailability adalah ketidakhandalan sistem. Ada sebuah persamaan Fading Margin untuk sistem Space Diversity.[2]

$$
F M=20 \log D+5 \log (2,5 \cdot a \cdot b)-5 \log U n A v_{\text {path }}-10 \log s+\frac{1}{2} v-15,4
$$


Keterangan :

$\begin{array}{ll}s & : \text { jarak antar antena diversity yang terletak vertical (m) } \\ a & : \text { faktor kekasaran bumi (terrain Roughness) } \\ b & : \text { faktor iklim } \\ U n A v_{\text {path }} & : \text { ketidakhandalan system (Unavailability) } \\ v & : \text { beda gain antar antena (dB) }\end{array}$

Dari persmaan (2) maka dapat diturunkan persamaan ketidakhandalan sistem atau Unavailability menjadi

$$
\begin{gathered}
F M=20 \log D+5 \log (2,5 \cdot a \cdot b)-5 \log U n A v_{\text {path }}-10 \log s+\frac{1}{2} v-15,4 \\
5 \log U n A v_{\text {path }}=20 \log D+5 \log (2,5 \cdot a \cdot b)-10 \log s+\frac{1}{2} v-15,4-F M \\
U n A v_{\text {path }}{ }^{5}=\frac{D^{20} \cdot 2,5^{5} \cdot(a \cdot b)^{5} \cdot 10^{\frac{1}{2} v}}{s^{10} \cdot 10^{15,4} \cdot 10^{F M}} \\
\text { UnA } v_{\text {path }}=\sqrt[5]{\frac{D^{20} \cdot 2,5^{5} \cdot(a \cdot b)^{5} \cdot 10^{\frac{1}{2} v}}{s^{10} \cdot 10^{15,4} \cdot 10^{F M}}}
\end{gathered}
$$

Keterangan :

$$
\begin{array}{ll}
s & : \text { jarak antar antena diversity yang terletak vertical (m) } \\
a & : \text { faktor kekasaran bumi (terrain Roughness) } \\
b & : \text { faktor iklim } \\
\text { UnA } v_{\text {path }} & \text { : ketidakhandalan system (Unavailability) } \\
v & \text { : beda gain antar antena (dB) }
\end{array}
$$

Hubungan antara kehandalan sistem dengan ketidakhandalan sistem pun dapat dihitung melalui persamaan di bawah ini.[2]

$$
A v_{\text {path }}=1-U n A v_{\text {path }}
$$

Keterangan :

UnA $v_{\text {path }} \quad$ : ketidakhandalan system (Unavailability)

$A v_{\text {path }}:$ kehandalan system (Availability)

\subsection{Metodologi Penelitian}

Alur proses Penelitian ini dapat dijelaskan pada gambar 3, dengan alur simulasi dengan menggunakan Pathloss 5.0 pertama tanpa menggunakan Space Diversity dengan pemodelan bersifat MIMO 2x2, selanjutnya simulasi dengan menggunakan Space Diversity dan yang terakhir menganalisis hasil simulasi.

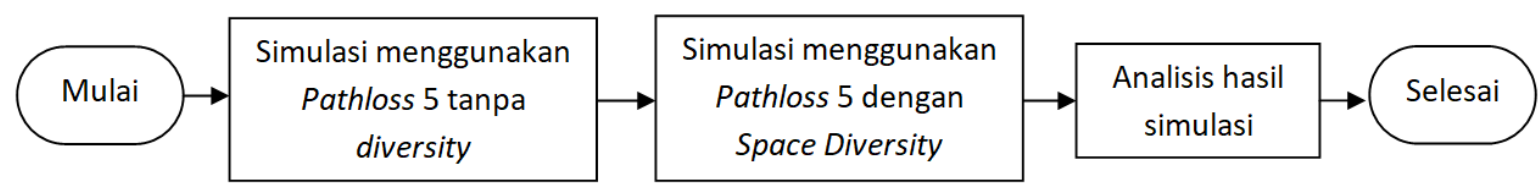

Gambar 3 Alur Proses Penelitian 


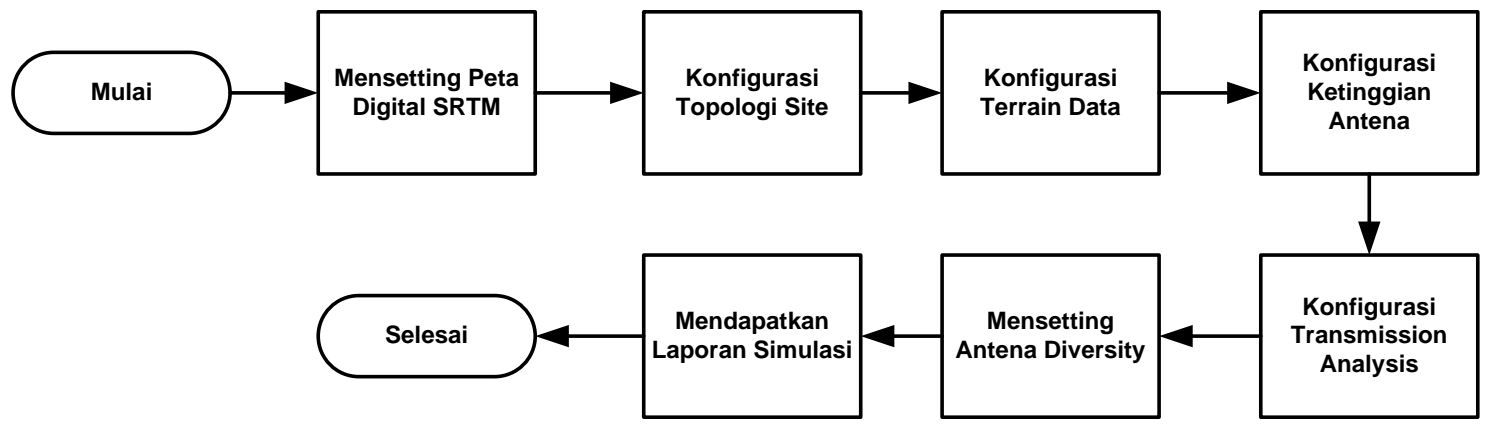

Gambar 4 Alur Proses Simulasi

Dalam melakukan simulasi dengan ataupun tanpa Space Diversity, parameter yang digunakan tetap sama, dilakukan pada siteCibatu Tiga, Bogor dan Dampyak Jonggol, Bogor, frekuensi yang digunakan adalah $23 \mathrm{Ghz}$, dan tinggi antena utama adalah $30 \mathrm{~m}$.

Tabel 1 Parameter Input

\begin{tabular}{|l|l|}
\hline Parameter Input & Nilai \\
\hline Site & Cibatu Tiga, Dampyak Jonggol \\
\hline Frekuensi & $23 \mathrm{Ghz}$ \\
\hline$\lambda$ (c/f) & $0,013043478 \mathrm{~m}$ \\
\hline Tinggi antena utama & $30 \mathrm{~m}$ \\
\hline
\end{tabular}

Dalam melakukan simulasi dengan Space Diversity, parameter yang diperlukan adalah ketinggian antena diversity. Sesuai dengan persamaan (1), tinggi antena diversity dapat ditentukan dengan $100 \lambda-200 \lambda$, dan dalam penelitian ini dilakukan simulasi diantara kedua nilai tersebut selisih nilai setiap $25 \lambda$.

Tabel 2 Parameter Space Diversity

\begin{tabular}{|l|l|l|}
\hline Nilai $\mathbf{p}$ & $\Delta \boldsymbol{h}(\boldsymbol{p} . \boldsymbol{\lambda})$ & $\mathbf{h}_{2}=\mathbf{h}_{1}-\Delta \boldsymbol{h}$ \\
\hline 100 & 1,304347826 & 28,69565217 \\
\hline 125 & 1,630434783 & 28,36956522 \\
\hline 150 & 1,956521739 & 28,04347826 \\
\hline 175 & 2,282608696 & 27,7173913 \\
\hline 200 & 2,608695652 & 27,39130435 \\
\hline
\end{tabular}

\section{PEMBAHASAN}

Setelah dilakukan simulasi dengan menggunakan Pathloss 5, didapatkan hasil seperti yang ditunjukkan pada gambar 5. Pada jarak 0 $\lambda$ merupakan link microwave tidak menggunakan diversity, availabilityyang didapatkan adalah 99,99975\%. Pada saat digunakan Space Diversity,

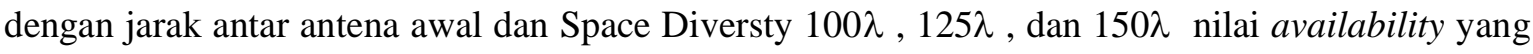
didapatkan adalah 99,99989\%. Pada saat digunakan Space Diversity, dengan jarak antar antena awal dan Space Diversty $175 \lambda$ dan 200入 nilai availability yang didapatkan adalah 99,9999\%. Dari grafik diatas menunjukkan adanya peningkatan availability pada link microwave yang menggunakan Space Diversity. 


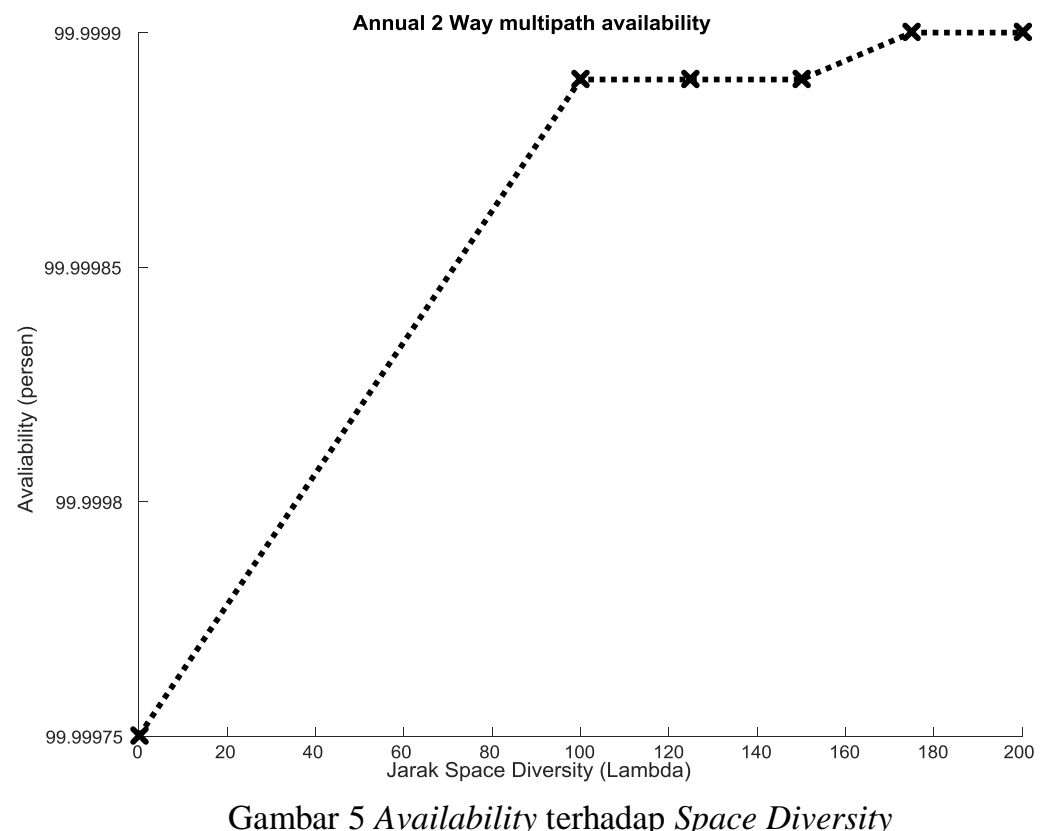

Pada simulasi yang telah dilakukan didapatkan pula Diversity Receive Signalseperti gambar 6. Pada Space Diversitydengan jarak $100 \lambda$, receive signal yang didapatkan adalah $-84,41 \mathrm{dBm}$. Pada Space Diversity dengan jarak $125 \lambda$, receive signal yang didapatkan adalah $-84,29 \mathrm{dBm}$. Pada Space Diversity dengan jarak $150 \lambda$, receive signal yang didapatkan adalah $-84,17 \mathrm{dBm}$. Pada Space Diversity dengan jarak $175 \lambda$, receive signal yang didapatkan adalah $-84,05 \mathrm{dBm}$. Pada Space

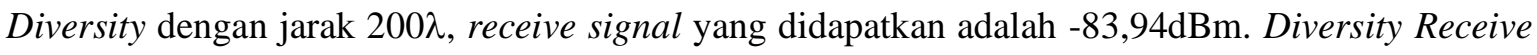
Signal tertinggi didapatkan pada 200 $\lambda$, semakin besar jarak antar antena, maka akan menghasilkan Diversity Receive Signal yang lebih tinggi.

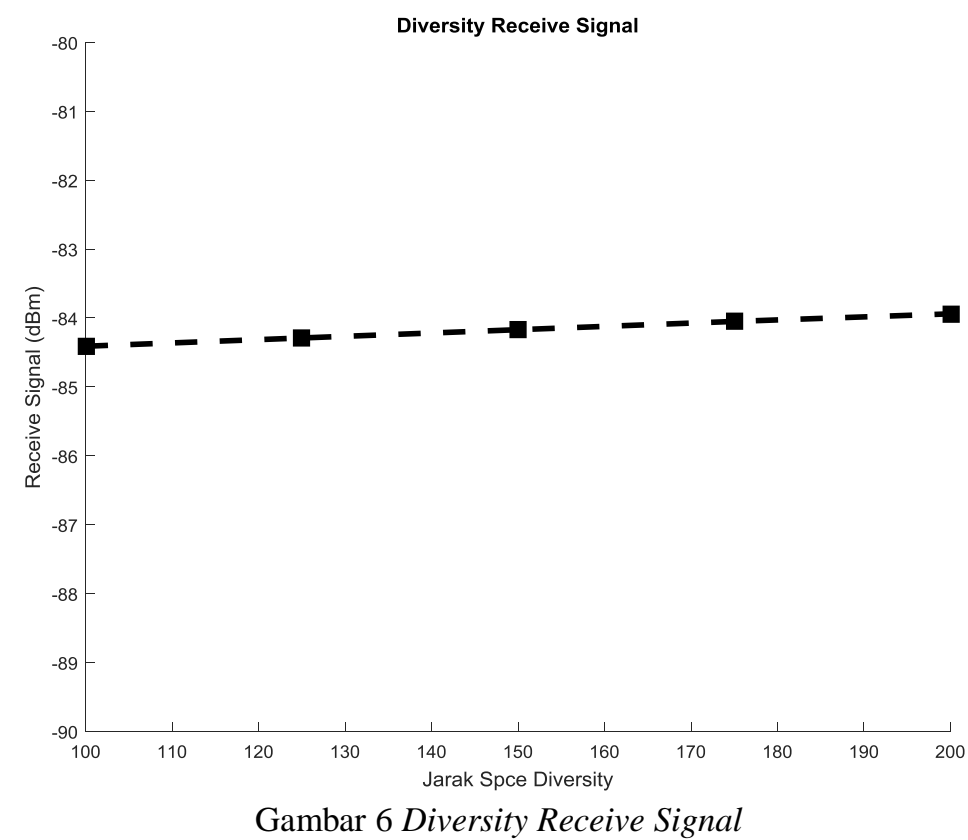




\section{KESIMPULAN}

Dari penelitian ini, dapat disimpulkan bahwa

1. Dengan menggunakan space diversity, availability dari link microwave dapat meningkat.

2. Diversity Receive Signal tertinggi didapatkan pada 200ג, dengan nilai Diversity Receive Signal adalah $-83,94 \mathrm{dBm}$.

3. Semakin besar jarak antar antena, maka akan menghasilkan Diversity Receive Signal yang lebih tinggi.

\section{DAFTAR PUSTAKA}

[1] T. Haslinda, "Analisis Jaringan Transmisi Microwave dengan Pathloss 4.0," Akatel Sandhy Putra, Purwokerto, 2012.

[2] A. Hikmaturokhman, Diktat Kuliah Gelombang Mikro, Purwokerto: Akademi Teknik Telekomunikasi Sandhy Putra Purwokerto, 2007.

[3] R. L. Freeman, Radio System Design for Telecommunications, Third Edition, United States of America: John Wiley \& Sons, Inc., 2006.

[4] R. G. Winch, Telecommunication Transmision System, United States: McGraw-Hill, 1998.

[5] N. Sachdeva dan D. Sharma, "Diversity: A Fading Reduction Technique," International Journal of Advanced Research in Computer Science and Software Engineering, vol. 2, no. 6, pp. 58-61, 2012.

[6] N. Desai dan G. D. Makawana, "Space Diversity for Wireless Communication-A Review," International Journal of Engineering Science and Innovative Technology, vol. 2, no. 3, pp. 405-410, 2013.

[7] A. Hikmaturokhman, A. Wahyudin, A. S. Yuchintya dan T. A. Nugraha, "Comparison analysis of passive repeater links prediction using methods: Barnett Vigants \& ITU models", 2017 4th International Conference on New Media Studies (CONMEDIA), pp. 142-147, 2017 